\title{
Ciudades creativas y pueblos con encanto: los nuevos procesos patrimoniales del siglo XXI*
}

\author{
Smart Cities and Charming Villages: \\ New Heritage Processes in the Twenty-first Century
}

\author{
Beatriz Santamarina Campos ${ }^{1}$ \\ Universitat de València \\ Camila del Mármol ${ }^{2}$ \\ Universitat de Barcelona
}

\section{RESUMEN}

Durante las últimas décadas hemos asistido a un crecimiento espectacular del fenómeno patrimonial. La eclosión patrimonial, entre otras cosas, puede ser leída como una cara más del tercer espíritu del capitalismo. El desembarco de la economía de los intangibles y el acento en la producción del valor de lo inmaterial ha cambiado las reglas del juego de la economía mundial. Nuestra hipótesis de partida es que hemos asistido a una importante transformación en las activaciones patrimoniales: del nacionalismo político, que impulsó el patrimonio colectivo en el XIX, hemos pasado al nacionalismo de consumo en el siglo XXI. En este contexto, este artículo analiza el distinto impacto que tienen los procesos patrimoniales en función de la posición que ocupan sus territorios en los mercados globales. Dicha posición incidirá en su carta de presentación apareciendo las ciudades creativas o los pueblos con encanto. Ambas formas son, en realidad, caras de un mismo proceso.

Palabras clave: Patrimonio; Economía de los intangibles; Ciudades creativas; Pueblos con encanto.

\section{SUMMARY}

The heritage phenomenon has undergone spectacular growth in recent decades in a boom that can be interpreted as an aspect of the third spirit of capitalism. The arrival of the economy of intangibles with its emphasis on this new production of value has changed the rules of the game for the global economy. In this article, we argue that a crucial transformation has taken place within the activation of heritage assets: we have moved from the political nationalism which triggered collective heritage in the nineteenth century, to a nationalism of consumption during the twentyfirst century. In this context, we focus on the different impact of heritage processes depending on

* Este trabajo se ha realizado en el marco de un proyecto de investigación titulado: "El patrimonio cultural y natural en tiempos de crisis. Retos, adaptaciones y estrategias en contextos locales", financiado por el Ministerio de Economía y Competitividad y el Programa FEDER. CSO201568611-R (MINECO/FEDER, UE).

${ }^{1}$ Correo electrónico: Beatriz.Santamarina@uv.es. ORCID iD: http://orcid.org/0000-0002-4170-7382.

${ }^{2}$ Correo electrónico: cdelmarmol@ub.edu. ORCID iD: http://orcid.org/0000-0002-1257-3370. 
where a location is positioned within global markets. This position will then condition the bid to become a smart city or charming village. We contend that both are two sides of the same coin.

Key words: Heritage; Economy of Intangibles; Smart Cities; Charming Villages.

\section{INTRODUCCIÓN}

Desde hace algunos años distintos autores destacan el vertiginoso incremento de las activaciones patrimoniales, la llamada fábrica de lo patrimonial ha derivado en una inflación patrimonialista cuanto menos paradójica (Heinich 2009; Bendix 2009). El patrimonio colectivo, como categoría polisémica, ha ido expandiéndose y resignificando cada vez más ámbitos de nuestras realidades sociales, culturales, económicas y políticas de principios de siglo. Hasta el punto que hoy se ha convertido en las agendas políticas en un asunto de primer orden. En paralelo, y al calor de la efervescencia patrimonializadora, los estudios del patrimonio han crecido, multiplicándose las disciplinas que proyectan sus discursos interpretativos dando lugar a crecientes escuelas de pensamiento. Explorado desde distintas perspectivas, el patrimonio como uso del pasado en el presente, ha sido cuestionado en su origen y desarrollo y criticado como discurso autorizado (Poulot 2006; Smith 2006). Asimismo, ha sido repensado desde la antropología económica y, más recientemente, abordado como ensamblaje de futuros y desde un giro ontológico (Macdonald 2013; Franquesa 2013; Harrison 2013; Bendix, Eggert y Peselmann 2012; Chaves, Montenegro y Zambrano 2014).

Hoy, el patrimonio, como fetiche metacultural (Kirshenblatt-Gimblett 2004) es un constructo que se expande con intensidad, desde mediados del siglo XX (Polout 2006; Choay 1996), coincidiendo con la eclosión de la industria del turismo global (MacCannell 1999), reconfigurando mercados, en creciente aumento, articulados alrededor de la autenticidad (Davallon 2010; Frigolé 2014; Santamarina y Moncusí 2015). La última adquisición del patrimonio institucionalizado ha sido la aparición de lo inmaterial en el seno de la UNESCO (Convención para la Salvaguardia del Patrimonio Cultural Inmaterial, París, 2003) contribuyendo a la colonización semántica del término. Evidentemente, esta inclusión puede ser leída desde múltiples visiones, pero responde, entre otras, a la transformación de la racionalidad de la economía neoliberal y al desembarco de la economía de los intangibles. En este sentido, puede ser interpretada en el contexto de las nuevas economías culturales (Arenheier y Isar 2008; Throsby 2001; Scott 2007) en la que sectores productivos alternativos, como las industrias de productos culturales o las actividades neo-artesanales, toman la delantera (Scott 2008; Comaroff y Comaroff 2009). Sin duda, las reglas del juego han cambiado en la economía neoliberal originándose una significativa transformación en la producción: el valor de lo material ha sido desplazo a favor del valor de lo inmaterial (Harvey 1998; Boltanski y Chiapello 2002; Comaroff y Comaroff 2009). El nuevo sistema económico surgido, global y globalizado, impacta tanto en los centros de producción globales como en las periferias locales transformando a su vez sus modos de producción y reproducción y forzando a nuevas respuestas ante las actuales coyunturas (Roigé y Frigolé 2010).

En este contexto, el análisis del constructo patrimonial no debe reducirse a un ámbito específico o limitarse a las cartografías hegemónicas de la UNESCO y fragmen- 
tarse en sus derivaciones naturales, culturales o intangibles. Más bien la realidad nos muestra lo contrario, entre las categorías normativas se suceden mediaciones complejas, demarcaciones confusas e hibridaciones constantes. Desde nuestro punto de vista, la etnografía nos permite embarcarnos en análisis complejos que reintegran los discursos y las políticas del patrimonio en entramados más amplios, donde se diluyen las propias narrativas que se proclaman. En esta perspectiva, nos interesa pensar el funcionamiento del dispositivo patrimonial teniendo en cuenta que no hay territorio (si los hay) que escape de una u otra forma a los imperativos patrimoniales subyugados a la lógica neocapitalista. Así, partimos de la premisa de que el patrimonio convierte el pasado y la autenticidad en un juego atado a la lógica de demandas mercantiles crecientes. La nueva economía política, marcada por las exigencias globales, la terciarización y la deslocalización, fuerza tanto a los centros clásicos de producción, que han perdido su posición competitiva, como a las periferias, en los márgenes de los polos de producción, a reinventarse, ora con lenguajes creativos, ora con retóricas prístinas. O dicho de otra forma, las ciudades, en su decadencia industrial y atrapadas en las carreras por la visibilidad, se han visto abocadas a la producción y reproducción de la creatividad. Ciudades competitivas, inteligentes e innovadoras se han multiplicado por doquier buscando la excelencia a través de la apuesta por la economía de los intangibles y la multiplicación de contenedores culturales. La proliferación de los denominados elefantes blancos ${ }^{3}$ son buena muestra de ello (Seisdedos 2006 y 2008; Markusen y Gadwa 2010; García 2004; Rius-Ulldemolins, Hernández y Torres 2015). Mientras tanto, los territorios que quedaron situados en los márgenes de la producción fabril, las zonas rurales y de montaña, reducidos ante las presiones de la agroindustria y los mercados globales, se han visto forzados a convertirse en vergeles de valores primitivos y refugio de las sociedades postindustriales (Sivaramakrishnan y Vaccaro 2006; Williams 2001; Lowe et al. 1993).

En este artículo queremos prestar precisamente atención a esos procesos de reinvención patrimonial que dan lugar paradójicamente a la reafirmación de las viejas dicotomías conformadas en la modernidad. Pensemos, además, que el patrimonio es tanto un producto de la modernidad como productor de la misma (Harrison 2013). De tal modo que asistimos a una narrativa donde las ciudades se visten de creativas y los pueblos se disfrazan de encanto. La retórica de ambos espacios, pródiga y clónica, nos muestra el recurso patrimonial como un poderoso motor económico. Nuestra hipótesis de partida es que hemos asistido a un importante giro copernicano en las activaciones patrimoniales: del nacionalismo político, que impulsó el patrimonio colectivo en el XIX, hemos pasado al nacionalismo de consumo en el siglo XXI. Para abordar todo ello, en primer lugar, proponemos un marco interpretativo desde dónde poder analizar nuestra propuesta. En segundo lugar, veremos a través de un caso de estudio, como una ciudad asume la nueva retórica patrimonial proponiendo un nuevo consumo cultural para no quedarse al margen de los nuevos mercados. En tercer lugar, nos acercaremos, también a partir de un estudio de caso, a una zona rural para ver, del mismo modo que en lo anterior, cómo articulan su respuesta ante las nuevas exigencias globales. Y, por último, cerraremos con unas breves conclusiones.

\footnotetext{
3 «En inglés y en francés la expresión elefante blanco es atribuida a posesiones que tienen un coste de manutención mayor que los beneficios que aportan o aquellas que proporcionan beneficio a otros pero que a su propietario únicamente le ocasionan problemas" (Seisdedos 2008: 9).
} 


\section{PATRIMONIO, DEL NACIONALISMO POLÍTICO AL NACIONALISMO DE CONSUMO}

Pese a los antecedentes señalados por algunos autores en siglos precedentes, podemos decir que el patrimonio colectivo tomó cuerpo en el XIX, apareciendo por primera vez el concepto, su definición y las primeras tentativas de su ordenación política y jurídica. El monumento, en sus distintas versiones, encapsuló, de forma magistral, las topografías patrióticas que irían legitimando los proyectos de los estados nacionales (Anderson 1983; Daniels 1993; Choay 1996; Poulot 2006). La cultura y la naturaleza, una vez cosificadas, fueron tanto objetos conquistables como fuente nacionalista e identitaria a través de la reinvención del pasado (Hobsbawm y Ranger 1988). El resultado fue la articulación de un patrimonio con un fuerte componente identitario, patriótico y nacionalista, donde los valores culturales/naturales se entremezclaban con valores estéticos, religiosos, históricos y legendarios. El programa patrimonial se moduló en la distinción y en el genio creativo como formas exclusivas y sublimes de representar a una colectividad permitiendo a través del mismo una suerte de continuidad histórica. Así, el patrimonio nacional se convirtió en una herramienta fundamental para dotar de legitimidad a los proyectos políticos, construyéndose lo patrimonial como un espejo identitario de un territorio común (Prats 1997). La identidad, despojada de atributos incómodos, se presentó como un tropo capaz de garantizar un pasado y un presente común para el futuro. La historia, la naturaleza y la cultura eran versionadas en singular para afianzar un proyecto pretendidamente plural y colectivo. Y a la vez eran instrumentos incuestionables de superioridad civilizatoria que legitimaban la distribución naturalizada de la dominación intra y extrafronteriza. Al mismo tiempo, el capital patrimonial aparecía como un poderoso abrigo frente a los procesos de aceleración y destrucción propios de la primera modernidad (Hernández et al. 2005). La aparición de la concepción del pasado, en el siglo XIX, como un territorio extraño y como marco de sentido, será condición esencial para que aparezca la construcción patrimonial (Lowenthal 1998), representando ésta una advertencia para resguardar un pasado escogido y exaltado y una evocación a la identidad colectiva. El patrimonio se activará como respuesta al desengaño del mundo tradicional y al arribo de la modernidad, al reencantamiento del mundo con la razón, la ciencia y el progreso, que tiene como corolario un regreso alegórico a un nuevo encantamiento compensatorio (tradición y pasado) (Ballart 1997; Ariño 2002; Hernández 2004). En cualquier caso, el patrimonio colectivo, en versión histórico-artístico a la europea, o en su modalidad natural a la norteamericana, se erigió a través de criterios ligados a la originalidad y a la belleza. Su declaración fue inequívoca al ser avalada por el desarrollo de las incipientes disciplinas académicas, que atestiguaban no solo el valor patrimonial sino también su transcendencia (Smith 2004). La autenticidad de la obra de arte o de la naturaleza vendrá certificada por el desarrollo de las ciencias que distinguían un original de una copia o una naturaleza intervenida de una prístina.

En los primeros compases del siglo XX, el cambio del Estado liberal al Estado social o intervencionista, producirá tanto un cuerpo jurídico sistemático para la conservación patrimonial (la tutela patrimonial del Estado será un deber) como un reconocimiento de su titularidad social (Ballart 1997; Hernández Hernández 2002). Pero será a mediados del siglo XX, tras la II Guerra Mundial y la llegada del Estado de bienes- 
tar, cuando va redefiniéndose, dejando atrás viejos corsés, apareciendo la noción de bien como una superación del viejo concepto de monumento. La formulación de carácter legendario-histórico decimonónico se irá desplazando hacia el énfasis en procesos significativos de la práctica cultural dando entrada al tercer sector en las activaciones patrimoniales. La noción de patrimonio irá democratizándose y dilatándose, al mismo tiempo que la expansión de la economía del ocio, la revolución tecnológica y de transportes y el crecimiento económico provocarán no solo la alianza entre patrimonio y turismo, (entrando la lógica económica en la racionalidad patrimonial), sino también procesos de malestar social y de destrucción acelerada (crisis ecológica, alienación social, etcétera) que auspiciarán demandas patrimoniales como una forma de contrarrestar el desasosiego de la modernidad avanzada. En este sentido, la Escuela de Frankfurt se hacía eco del creciente malestar y acuñaba, por primera vez, el término industrias culturales casando dos términos, en principio opuestos, y señalando los incipientes cambios en la producción (Adorno y Horkheimer 1994 [1944]). Por lo que respecta al patrimonio, la nueva cartografía patrimonial vendrá definida por el peso cada vez mayor de las agencias internacionales, la especialización disciplinaria, el desarrollo de cuerpos jurídicos y la entrada de la globalización en el seno de lo patrimonial apareciendo su versión metacultural bajo el manto del Patrimonio de la Humanidad (Kirshenblatt-Gimblet 2004).

En el último tercio del siglo XX, de hecho, asistiremos a un crecimiento continuado de las activaciones patrimoniales, con presencia cada vez mayor de los nuevos agentes patrimoniales, y en un paisaje ya de producción posfordista donde las reglas de la economía mundial han cambiado. La configuración fordista-keynesiana (Harvey 2012), el llamado capitalismo social, entraba en quiebra en los 70, coincidiendo con la hiperacumulación y la crisis energética, y daba paso a una reestructuración global del capitalismo y al neoliberalismo más insaciable (Castells 1999; Harvey 2005). Ahora bien, el neoliberalismo, como ha sido señalado, "is not simply an economic structure, it is a philosophy" (Treanor 2005: 10), ha ido impregnando todas las esferas y cambiando las reglas de juego que dará lugar al Estado de mercado (Treanor 2005; Harvey 2005). El neoliberalismo incorpora una nueva configuración de creencias y valores, e instaura una reconceptualización del mundo social y cultural. La lógica neoliberal supone la continua expansión del mercado (Treanor 2005) dando lugar a una carrera desenfrenada por la competencia entre personas y territorios avocándolos a la búsqueda incesante de innovaciones y nuevas transacciones. El tesón por englobar todas las acciones humanas bajo el dominio del mercado (Harvey 2005) ha dado lugar a la expansión al ámbito de lo cultural, movilizando lo que se llega a conocer como cultural economy (Anheier y Yudhishthir 2008; Pratt 2008; Throsby 2001).

En este contexto de mundialización neoliberal, el desembarco de las industrias culturales y de entretenimiento y la creciente mercantilización de la cultura y el ocio irán desarrollándose en busca de un nuevo mercado guiado por nuevos valores y sintetizado en las llamadas industrias creativas. Reflejo de los nuevos tiempos, por un lado, son las políticas culturales impulsadas por la UNESCO en los ochenta, que estuvieron acompañadas políticamente, por primera vez, por la adopción de industrias culturales en la publicación del libro Industrias Culturales: El futuro de la Cultura en juego (UNESCO 1982) o en la definición del término en la Conferencia Mundial de Políticas Culturales (México, 1982) que dio paso a su consolidación institucional que 
venía cuajándose desde los 70 (Hesmondhalgh 2007; Carrasco y Saperas 2011). Como señalan Carrasco y Saperas se produce aquí un importante giro ontológico:

"la industria cultural pasa de ser un elemento discursivo clave para la comprensión de la pérdida de la capacidad crítica y negativa de la cultura como consecuencia de los mecanismos ideológicos de producción, distribución y consumos típicamente industriales a los que se ve sometida, a designar una nueva realidad cultural" (2011: 156).

Y, por otro, podemos ver los primeros compases hacia el reconocimiento del patrimonio inmaterial, en la ya nombrada conferencia de México, en la creación también 1982 del Comité de Expertos Gubernamentales en la Salvaguardia del Folclore o de manera más firme, como primer instrumento normativo, en la Recomendación sobre la Salvaguarda de la Cultura Tradicional y Popular adoptada en París en 1989 que marcará lo que será el final de siglo y la agenda de la nueva centuria. Como vemos, lo patrimonial despegaba como una forma resuelta de dar respuesta a las inquietudes sociales y de mercado en una sociedad del hiperconsumo y de la individualización y anticipaba la eclosión de las nuevas imbricaciones y usos de la cultura en el contexto neoliberal.

El siglo XXI no ha hecho más que reforzar este fenómeno de crecimiento patrimonial provocándose una inflación, utilizando la expresión de Heinich (2009), que responde, por un lado, a una demanda y un consumo patrimonial creciente y, por otro, a la mundialización (y también localización) de su producción. Esta inflación patrimonial debe interpretarse teniendo presente fenómenos interrelacionados que, como acabamos de señalar, empezaban a cuajarse en las últimas décadas del XX. Desde nuestro punto de vista, el patrimonio se sitúa como un potente productor de sentidos en un mundo caracterizado por procesos cruzados de homogeneización, heterogeneización e hibridación en contextos marcados por la desterritorialización y la reterritorialización (Appadurai 2001; García Canclini 1999). La hipermodernidad — con la contracción espacio-temporal, la aceleración de acontecimientos o la globalización de capitales, culturas y personas (Harvey 1998) — transforma las coordenadas para situarse y pensarse en el mundo. Además, los procesos de secularización, racionalización y desencantamiento obligan a buscar nuevos anclajes en una comunidad líquida y fragmentada. Pero, también el patrimonio gracias a la nueva economía neoliberal —con la reestructuración, deslocalización y la terciarización de la economía - se ha situado como un producto estrella de consumo al condensar en su representación valores fuertemente demandados. En este contexto, la fetichización y espectacularización patrimonial expresa esa búsqueda de valores, cada vez más apreciados y vinculados a un tiempo y un espacio prefordista (lentitud, manufactura, originalidad, autenticidad, transcendencia...). Y las formas emergentes patrimoniales condensarían el llamado espíritu del tercer capitalismo al ofrecer valores añadidos: en lo intangible y lo inmaterial está la experiencia auténtica más allá de lo material (lo singular frente a lo masificado) (Boltanski y Chiapello 2002). Pero este nicho de mercado ha traído, en contrapartida, la banalización y la comercialización de la cultura y la naturaleza donde el acento en los beneficios rige cualquier lógica ya desregularizada. De forma paradójica, el anhelo por alcanzar la autenticidad y la transcendencia, provocado por las reglas de juego neocapitalista, termina provocando que aparezca todo un marketing de la autenticidad y la transcendencia. La lógica es sencilla: el mercado responde con más merca- 
do. El enorme crecimiento de productos y servicios patrimoniales-turísticos, reflejo del tránsito entre el turismo fordista y posfordista, se ha convertido en el nuevo El Dorado para distintos territorios que buscan estar situados en el mapa. La competición entre territorios, por entrar en los circuitos, ha desarrollado diferentes estrategias de comercialización del patrimonio, multiplicándose las marcas y los sellos como mediadores de la producción de un pasado cada vez más efímero y mercantilizado.

En cualquier caso, lo que nos interesa subrayar es que de las formas patrimoniales del XIX a las activaciones patrimoniales del XXI ha habido un largo camino donde se han ido mudando las representaciones patrimoniales y donde lo patrimonial ha ido acomodándose a las nuevas demandas políticas, sociales y económicas. Si el patrimonio decimonónico respondía a un proyecto político basado en la distinción y en la creación de potentes imaginarios nacionales, el patrimonio hoy se presenta como un proyecto económico definido como un producto de consumo insertado en capitales transnacionales. Del Estado liberal y el nacionalismo político, hemos pasado al Estado de mercado y al nacionalismo de consumo. El aparato patrimonial hoy no es solo productor de distinciones y valores globales sino también de mercancías emergentes. Las modulaciones, como señalábamos más arriba, han sido sustituidas en los procesos productivos: del acento en lo material hemos pasado a subrayar lo inmaterial. Imbuidos en una mercantilización de la cultura y la naturaleza se apuesta por la diferencia, por el imaginario colectivo, por lo vivido (experiencias) y por los procesos, frente a la distinción, el genio creativo, la contemplación y los objetos de antaño. Así, el reconocimiento dado por UNESCO en 2003 al incluir lo inmaterial como Patrimonio de la Humanidad puede ser leído, al menos, desde dos perspectivas distintas y complementarias. De una parte, suponía una compensación simbólica, una doble reparación moral por parte de la UNESCO. Doble porque reconocía, al mismo tiempo, el carácter elitista refugiado en la concepción humanista de la cultura (que había impedido el reconocimiento institucional y jurídico del ahora llamado patrimonio inmaterial) y la condición eurocéntrica de sus declaratorias (que habían dejado un mapa desequilibrado de la distribución patrimonial mundial con territorios sobrepatrimonializados y subpatrimonializados) (Santamarina 2013; Smith y Akagawa 2009). Y de otra, sintonizaba con los nuevos mercados donde la distinción entre alta cultura y cultura popular se diluye en busca de nuevos productos cargados de autenticidades y donde lo inmaterial encajaba de lleno con la nueva filosofía neoliberal.

Ahora bien, el impacto de las nuevas condiciones de mercado es diferente dependiendo del territorio y su vinculación con los focos de producción clásicos del capitalismo. En cualquier caso, lo que interesa reseñar es que tanto los enclaves centrales como las zonas periféricas están condenados a redefinirse, ante los nuevos imperativos neoliberales, si quieren sobrevivir. Para ello, la economía de lo inmaterial o de los intangibles se ha convertido en una herramienta fundamental en la configuración de las nuevas realidades urbanas y rurales auspiciándose diferentes estrategias políticas de mercantilización que responden a las representaciones y viejas demarcaciones de la primera modernidad. Al decir esto lo que queremos subrayar es que se ha producido un proceso paralelo que responde a la lógica decimonónica. A finales del XIX aparecen y se desarrollan, de forma paralela, los procesos de patrimonialización cultural, natural e inmaterial y en ellos se condensan los principios de edificación moderna (separación de dominios, depuración de espacios epistemológicos y clasifica- 
ción de formas de conocimiento) (Foucault 1970; Latour 1993; Haraway 1995; Mignolo 2012). El monumento nacional, histórico o natural, encapsuló el gusto y los criterios de las élites sobre la base de sus historias, memorias y territorios creando poderosas iconografías nacionales a partir de ellos. Por su parte, el patrimonio inmaterial fue relegado a un producto natural de un pueblo (Bortolotto 2011), donde lo folclórico, lo rústico y lo popular fue puesto en valor a través de los primeros museos tradicionales al aire libre (Santamarina 2008). Si el genio creativo se utilizó para situar los monumentos y museos en las grandes capitales, la naturalidad contenida en el folclore sirvió para emplazar lo inmaterial en los pueblos. De esta forma, las demarcaciones políticas establecidas funcionaron como activadores de conocimiento y reconocimiento (autenticidad), a partir de distintas lógicas (la autenticidad del patrimonio cultural se definía frente a la falsificación y la del patrimonio inmaterial frente a lo artificial). Esto provocó una jerarquización patrimonial, a partir de la asignación de valor, de la que todavía somos deudores. Nuestra premisa es que esa herencia epistemológica se ha mantenido hasta nuestros días, de tal forma que las ciudades creativas y los pueblos con encanto, se corresponden al genio creativo y a la naturalización del folclore.

\section{LA CIUDAD CREATIVA: NUEVOS PATRIMONIOS}

Como acabamos de señalar las reglas del juego han cambiado para todos los territorios, impactando de formas diversas. Por ello nos ocupamos ahora de analizar su huella en el ámbito urbano a partir de la transformación sufrida en una ciudad concreta, Valencia. Los cambios experimentados en esta urbe responderían a la redefinición del modelo de urbanismo empresarial (Harvey 1991) dando lugar a la aparición en las agendas políticas de la llamada New Urban Policy (NUP). Modelo que se ha extendido con rapidez por las urbes europeas y españolas ${ }^{4}$ y que se fundamenta en las políticas competitivas neoliberales (Swyngedouw, Moulaert y Rodríguez 2002; Rodríguez y Vicario 2005). La nueva política económica (desregularización, privatización, flexibilización del mercado laboral, descentralización espacial) y urbana (privatización de fondos públicos, marketing urbano, grandes proyectos, eventos mediáticos, desarrollo inmobiliario) han reconfigurado numerosas ciudades de nuestro entorno (Swyngedouw, Moulaert y Rodríguez 2002)5. La ciudad creativa (inteligente, sostenible e innovadora), articulada sobre el maridaje entre descomunales proyectos arquitectónicos, grandes eventos y estrategias profusas de promoción han reconstruido imágenes y demandas. Las políticas implementadas han dado lugar a un nuevo régimen

${ }^{4}$ El fenómeno ha sido ampliamente estudiado, véase, como botón de muestra en nuestro país, Cucó (2013a y b), Delgado (2007), Rodríguez (2013), Esteban (2007) entre otros muchos. Para Europa se puede acudir a García (2004 y 2008), Gold y Gold (2008), Connolly (2013) o Swyngedouw, Moulaert y Rodriguez (2002).

${ }^{5}$ Pese a que no podemos detenernos en ello, téngase en cuenta todo lo que se desprende de estás políticas neoliberales. En este sentido, como ha sido señalado, "one of the key components of the new mode of socioeconomic regulation in cities has been a gradual shift away from distributive policies, welfare considerations, and direct service provision towards more marketoriented and market-dependent approaches aimed at pursuing economic promotion and competitive restructuring" (Swyngedouw, Moulaert y Rodríguez 2002: 553). 
patrimonial que, en la mayoría de casos, ha dejado de trasfondo un paisaje de elefantes blancos (Rius-Ulldemolins, Hernández y Torres 2016). Elefantes bien visibles en la geografía valenciana, véase, por ejemplo, la Ciudad de la Luz en Alicante o la Ciudad de las Artes Escénicas en Sagunto.

Si atendemos a lo sucedido en la ciudad de Valencia, en las dos últimas décadas, podemos observar como las instancias políticas, Generalitat Valenciana y el Ayuntamiento de Valencia, han impulsado estrategias públicas neoliberales articuladas en actuaciones urbanas y culturales, de gran calado, gracias a un contexto económico favorable. El objetivo de este despliegue de medios, sin parangón, era crear nuevas ficciones patrimoniales para entrar en los circuitos turísticos y financieros en un mercado global cada vez más competitivo. De hecho, como ha sido señalado, la transformación impulsada a través de la fórmula de la competitividad, la excelencia y la creatividad trataba de recobrar para Valencia el movimiento centrífugo que había tenido antes la ciudad como polo de atracción de la producción industrial (Prytherch 2009; Prytherch y Boira 2009). Esta última lógica, la sustitución del polo industrial por el polo patrimonial buscaba nutrirse de un nicho propio para ser visible en las cartografías hegemónicas de mercado. A la vez que daba respuesta a los propios cánones productivos impuestos por la economía neoliberal, desplazando la producción material por la inmaterial (Boltanski y Chiapello 2002; Harvey 2005; Comaroff y Comaroff 2009). La apuesta por la economía de los intangibles y la proyección de la ciudad hacia el turismo de contenedores se materializó en la construcción de complejos monumentales y museístico (entre otros la Marina Real Juan Carlos I, Palacio de Congresos, Veles $e$ Vents $)^{6}$, aderezados de competiciones o encuentros internacionales exclusivos de alto impacto mediático (America’s Cup, Global Champions Tour, Valencia Street Circuit, Valencia Open 500, MTV Winter Festival ${ }^{7}$ y con campañas promocionales espectaculares y en nuevos soportes publicitarios, como "Valencia, increíble pero cierta" (Premio City Golden Gate al mejor spot turístico de cine y televisión del año en 2009) o "Mira Valencia con otros ojos" (Premio City Golden Gate al video turístico más innovador en 2011).

La salida política a la reconversión creativa, ante la fracasada reconversión industrial y tecnológica, se presentaba como la única vía para una ciudad castigada por el tercer espíritu del capitalismo y esto mismo legitimaba la apuesta. El programa revestido de posmodernidad se puso en marcha como activador resuelto de nuevos bienes patrimoniales como generadores de riqueza. Para su consecución las tecnologías del marketing, la producción de una nueva iconografía (city branding) y el negocio y la gestión de la marca (brand management), a través de la creación de potentes agencias público-privadas ${ }^{8}$, se pusieron a trabajar para la edificación y proliferación de

\footnotetext{
${ }^{6}$ Por dar cuenta de la magnitud de proyectos impulsados piénsese que su oferta museística se multiplicó por tres en una década (Martí 2010). Abriéndose, por ejemplo, en apenas seis años el Institut Valencià d'Art Modern (IVAM), el Museu de Ciències Naturals, el Museu Valencià de la Il.lustració i de la Modernitat (MUVIM) y el Museu d'Història de València.

${ }^{7}$ Nótese la utilización de la lengua inglesa para la difusión y publicidad de los eventos como estrategia no solo de captación sino de exclusión.

${ }^{8}$ Sirva como ejemplo la creación, en el 2004, del Centro de Estrategias y Desarrollo de Valencia organismo dirigido por el Ayuntamiento de Valencia (hoy ya desaparecido). Su finalidad era mejorar la imagen internacional y fomentar el turismo (Díaz Orueta 2010; Martí 2010).
} 
nuevas estructuras simbólico-clónicas (elefantes blancos) (Bélanger 2005; Bennet 2005; Kavaratzis y Ashworth 2005; Seisdedos 2006; Ruiz y Santamarina 2013). Y curiosamente, o mejor dicho de forma paradójica, esta profusión clónica — repetición idéntica de un patrón - ha sido tildada de creativa y patrimonial. No puede dejar de sorprender que el triunfo de la mercantilización del espacio público se dibuje bajo el paraguas de una creatividad clonada y privatizada. Del mismo modo resulta paradójico que la puesta en circulación de nuevos activos patrimoniales entre en contradicción con el principio de la escasez imperante en la puesta en marcha de la lógica patrimonial (García 1998; Lacarrieu 2008).

Las políticas públicas valencianas apostaron por numerosos programas de intervención en la ciudad de Valencia ${ }^{9}$ cambiando su imagen, de manera radical, y su fisonomía. Entre todos ellos, es destacable la Ciudad de las Artes y las Ciencias (CAC) porque comprime magníficamente la transformación ejecutada, la mercantilización de la imagen y la consecución de una marca ${ }^{10}$ tan resueltamente creativa como potencialmente productiva (Rausell 2010; Puche y Obiol 2011; Santamarina y Moncusí 2013a; Cucó 2013a y b). La CAC representa bien la apuesta por los intangibles (titánico proyecto de un arquitecto estrella; eje neurálgico de eventos; vasto gasto público ligado con capital privado y crecimiento inmobiliario) y el éxito institucional del brand management (Rausell 2006; Gaja 2008; Díaz Orueta 2009 y 2010; Cucó 2013a y b). Miles de metros cuadrados disponibles, y olvidados en un cauce seco, y ubicados cerca de una zona degradada por el pasado industrial, serían transformados en un enorme complejo cultural como marca de la Valencia del siglo XXI y como motor económico y creativo.

En cualquier caso, lo que nos interesa señalar es que la CAC encapsula la mutación experimentada en los referentes patrimoniales. Pensemos, por ejemplo, en la primera marca turística oficial de la ciudad desarrollada, a principios del siglo XX, bajo el sello "Ciudad de las Flores". Su creación se moduló en símbolos costumbristas valencianos que se han mantenido durante décadas (Obiol 2009; Martínez Gallego 2010; Puche y Obiol 2011). De la ciudad de las flores a la CAC hay un salto cuantitativo y cualitativo que ha modificado hasta el skyline de Valencia, del pasado histórico con edificaciones medievales (Toores de Serrano o Quart), hemos saltado al futuro con esqueletos futuristas (Hemisfèric, Palau de les Arts Reina Sofía, Ágora o puente del Assut de l'Or, todos en la CAC) (Santamarina 2014). La CAC ha descartado cualquier modulación histórica e identitaria presentándose como vanguardista, cosmopolita y galáctica (utilizando la misma terminología institucional puesta en circulación). Los elementos y argumentos nacionalistas de las primeras activaciones patrimoniales han sido sustituidos por discursos sobre el nuevo consumo cultural. ¿Cómo se ha logrado patrimonializar tan magna empresa? La representación de la CAC para el turista, como imagen de la ciudad, se ha modulado, sorprendentemente, en la autenticidad (piedra

\footnotetext{
${ }^{9}$ La mayoría de ellos resultan a día de hoy insostenibles. Además, con el impacto de la crisis económica, muchos han sido abandonados o forzados a reformularse para dar cabida a otros usos de dudable carácter.

${ }^{10}$ En este sentido, cabe señalar que todas las guías turísticas de Valencia tienen hoy en su portada la CAC, siendo ésta la imagen proyectada de la ciudad al exterior (Santamarina y Moncusí 2013b).
} 
angular de las activaciones patrimoniales). Esto se ha logrado gracias a un ejercicio complejo de recontextualización y fusión sobre viejos elementos patrimoniales. El discurso institucional ha casado lo moderno, lo tradicional, lo histórico y lo vanguardista en una misma narración, lo que ha permitido dotar, por contagio, la ansiada autentificación de las estructuras clónicas. En las guías turísticas y en las campañas publicitarias desplegadas es posible otear cómo la autenticidad proviene de la veracidad del relato ante lo inimaginable (Valencia, increíble pero cierta") (Santamarina y Moncusí 2013b y c) y cómo su contextualización en un patrimonio previo evita la necesidad de su legitimación. Valencia ha conseguido ofrecer al turista, anheloso de múltiples experiencias fugaces, un relato ficticio a la vez que auténtico, por imposible que parezca, encontrando en la historia y la tradición la fuente de autenticidad antes nega$\mathrm{da}^{11}$. Quizás, por todo ello, Valencia es un buen ejemplo de cómo la especulación, la espectacularización y la mercantilización pueden invadir el lugar que, en tiempos pasados, desarrollaba el nacionalismo en los procesos de patrimonialización. Ahora bien, nótese que en el envite por jugar dentro de los mapas globales de la excelencia, el nuevo rostro de Valencia ha tenido un precio altísimo. Por un lado, su articulación ha desmerecido los referentes de identificación locales y, por otro, ha puesto en riesgo la propia sostenibilidad de la ciudad.

\section{PUEBLOS CON ENCANTO: EL CASO DEL ALT URGELL EN CATALUÑA}

Pero si las nuevas exigencias globales obligaron a las zonas urbanas a redefinirse, las rurales no han escapado de esa lógica para garantizar su propia supervivencia. Las transformaciones que han tenido lugar en estas áreas responderían a la restructuración del capitalismo tardío, ante una realidad que se caracteriza por la dificultad de incrementar la producción y asegurar la explotación rentable de los terrenos agrícolas ${ }^{12}$ (Cloke 1989). La transición de un modelo productivista a otro post-productivista (Cloke y Goodwin 1992; Marsden et al. 1993) ha reconfigurado parte de estos territorios ${ }^{13}$. Frente al predominio de una agricultura intensiva e industrial, con un fuerte apoyo del estado, y orientada hacia el continuo aumento de la productividad (Lowe et al. 1993) asistiremos, a partir de mediados de la década del 80, a un cambio sustancial en esta visión: del acento en la producción se pasa a la modulación en el consumo. La traslación es importante para entender las nuevas maneras de producir valor en

\footnotetext{
${ }^{11}$ Pensemos en el enunciado constantemente repetido "Cuentan muchas historias sobre esa ciudad, y todas son ciertas" del anuncio "Valencia increíble pero cierta" o la llamada de atención de "Mira Valencia con otros ojos" que insiste en una Valencia de otra dimensión, pero repite la misma muletilla que el anterior: la ciudad es tan "increíble" como "cierta". Estas dos campañas publicitarias fueron las más importantes de las lanzadas para la difusión de la ciudad. En ambas se certifica la verdad a través de lo cierto.

${ }^{12}$ Desde los años 80, la geografía rural ha venido analizado y señalando las distintas transformaciones en el ámbito de lo rural. Véase, entre otros, Cloke (1989), Cloke y Goodwin (1992) y Marsden et al. (1993).

${ }^{13}$ En esta línea, Wilson (2007) propone acercarse a la dicotomía conceptual que se ha planteado entre productivismo y post-productivismo, no tanto como dos estadios definidos, sino más bien como polos de un espectro que pueden explicar la transformación de las distintas zonas rurales europeas.
} 
estas zonas. El énfasis de la producción agrícola va siendo desplazado por la aparición del consumo de los territorios rurales (Wilson 2007: 3). La nueva lógica de la economía neoliberal obligaba a reordenar los criterios productivos remplazando la producción material por la inmaterial, de forma similar a lo que sucedía en nuestro caso anterior. Baste con asomarse a las políticas de la Unión Europea para observar cómo se ha impuesto una clara voluntad de restructuración territorial, definida a través de las Políticas Agrarias Comunes. En las mismas es significativa la apuesta por la reducción de la agricultura y la ganadería extensivas. De hecho, solo aquellas zonas consideradas altamente productivas quedarían reservadas a la producción agrícola y ganadera, lo que obliga a una profunda resignificación de los usos de la tierra en aquellas zonas consideradas de bajo rendimiento (Tulla 1994).

Para acercarnos a estas transformaciones nos centramos en un caso concreto: la comarca del Alt Urgell en el Pirineo catalán. Este territorio ocupa una serie de valles que nacen en su mayor parte de una llanura central atravesada por el río Segre. La población se concentra mayormente en la capital, la Seu d'Urgell, dejando vacíos habitacionales importantes y bajos índices de población en los valles aledaños. La economía, centrada en una agricultura de subsistencia propia de los pueblos rurales de principios de siglo, fue transformada por el establecimiento de un modelo de producción intensivo de leche destinado a alimentar las fábricas de transformación láctea de la Seu d’Urgell (Del Mármol 2016; Del Mármol y Vaccaro 2015). Pero la década del 80 trajo consigo la inclusión de España en la Comunidad Económica Europea y con ello la aplicación de cuotas de producción de leche dando paso a una reestructuración del sector. Las granjas se concentraron desde entonces cerca de la capital de comarca, dejando los valles más lejanos desprovistos de un modelo de producción viable.

Si en las ciudades podemos hablar de nuevas estrategias ante las exigencias del capitalismo neoliberal, las zonas rurales también presentan nuevas políticas económicas que se adaptan a las condiciones cambiantes. Ante la redefinición productiva como consecuencia de la entrada al mercado europeo, las opciones económicas se ven claramente influenciadas por la presencia de ayudas y subvenciones procedentes de Bruselas. Se imponen nuevas condiciones discursivas, el territorio pasa a ser entendido en clave patrimonial. Una nueva legislación para zonas de montaña abre la puerta a estas nuevas lecturas: donde antes se veían territorios estancados con una agricultura poco productiva y aislados de los centros de consumo, en la actualidad se conciben en términos de reservas de naturaleza y de valores de autenticidad. Las relaciones sociales, los modos y prácticas de producción del pasado, así como las fiestas, la arquitectura y muchas otras especificidades locales, pasan a ser consideradas marcas de una autenticidad ligada a la ruralidad.

Desde la década del 80 se crean varios parques naturales y se multiplican las categorías de espacios naturales protegidos desde diversas instancias (Generalitat de Catalunya, Estado Español, Unión Europea). El medio, antes entendido como contexto de vida y de producción, escindido en la concepción campesina entre aquello salvaje y domesticado - un espacio cultivado ganado a pulso contra las inclemencias del clima y del bosque (Frigolé 2012)_; es ahora producido para el visitante urbano como reducto de naturaleza prístina. Los parques y espacios protegidos se articulan en el discurso global de la conservación natural (Santamarina 2016), pero centran gran par- 
te de sus prácticas y actuaciones en la conversión de lo natural en algo visitable, vendible y experienciable. La natural naturaleza se ha convertido en un negocio creciente y rentable (Igoe, Neves y Brockington 2010; Brockington y Duffy 2010; Holmes 2011; Buscher et al. 2012). En la carrera por la singularidad que marca los esfuerzos retóricos y de marketing de los territorios, cada parque busca sus señas de identidad, sus animales emblemáticos y sus estilos de vida auténticos y tradicionales que los definan y atraigan al visitante obnubilado por la promesa de una experiencia más cercana a la naturaleza y más verdadera. La espectacularización de la naturaleza idealizada va acompañada por una restitución metonímica que convierte todo lo que toca en natural (sean paisajes, personas, productos, cosas, prácticas o vivencias) y, por ende, en auténtico.

Igualmente, la legislación sobre urbanismo se orienta a una protección de lo que se cataloga como arquitectura tradicional, garantizando la reproducción de una serie de imágenes de autenticidad en gran parte de los pueblos semiabandonados de la comarca (Del Mármol 2017). La madera, los techos de tejas de barro y las casas de piedra son elementos ahora protegidos, cuidadosamente definidos como producto de una arquitectura tradicional que se hereda de un pasado lejano en el que los habitantes extraían con sus manos los materiales del entorno para construir sus viviendas, en una metáfora de la conexión que las comunidades del pasado mantenían con el medio. Un visitante poco avezado en las ficciones del capitalismo avanzado podría confundir fácilmente los efectos de antigüedad conseguidos a través de sofisticadas técnicas de envejecimiento de tejas de barro o de la madera, por una longevidad certificada producto de las lluvias y vientos de cientos de años. El transcurrir del tiempo en sí mismo, y su marca perceptible en el objeto, es una parte fundamental del aura señalada por Benjamin (2007). Esto ha dado lugar a una industria específica que se dedica a la reproducción de esta pátina miraculosa que ya no se consigue a través del devenir del tiempo sino gracias al avance de los conocimientos químicos y de decoración.

Esto se completa con la multiplicación de museos y centros de interpretación, infraestructuras destinadas al visitante que son muchas veces financiadas solo hasta su construcción, siendo su mantenimiento y activación abandonados en manos de pequeños ayuntamientos locales sin capacidad económica (Abella, Alcalde y Rojas 2012). El museo del pagès, un clásico que se reproduce una y otra vez, se acompaña en el Alt Urgell de una serie de pequeños museos rurales que celebran los oficios del pasado, vestigios románticos y aislados de un modo de producción complejo que ha desaparecido: el museo dels Raiers, de les Trementinaries, de la Vinya, y un largo etcétera (véase Del Mármol 2012; Frigolé 2005). La producción artesana se multiplica y se adapta a los deseos de consumo de lo rural. La capital de comarca, la Seu d'Urgell, convierte una tradicional feria ganadera en una celebración del queso artesano, en una carrera por la especialización de los territorios y la creación de marcas que garanticen la atracción de visitantes ante la multiplicación de la oferta. Gastronomía, naturaleza y cultura se conjugan como retóricas de autenticidad ofreciendo una vuelta a un pasado idealizado, contenedor de imágenes cientos de veces reproducidas en los folletos turísticos.

Los cambios analizados no constituyen un caso aislado, por el contrario se refieren a transformaciones que se repiten en otras zonas rurales del ámbito europeo. Woods 
y McDonagh (2011: 156) identifican características comunes en las estrategias de desarrollo de las áreas rurales europeas, basadas en el abandono de las inversiones foráneas para centrarse en la movilización y revalorización de recursos internos. Ya no se trata del aprovechamiento de recursos naturales, sino de la identificación de nuevos activos plausibles de ser activados y que se resumen en los nuevos usos del patrimonio rural. Se impone un nuevo consumo de la ruralidad que impacta en estas zonas junto a otras dinámicas propias de la movilidad global como las nuevas relaciones con los centros urbanos, las prácticas de urbanización y de gentrificación rural, así como las nuevas estrategias de desarrollo basada en los usos sostenibles (Woods 2012: 2; Vlès 2014). El turismo y el patrimonio destacan entre estas últimas como estrategias fundamentales (Marsden y Sonnino 2008; Bell y Jayne 2010). Incluso distintos autores han analizado las políticas europeas para zonas rurales, como la Política Agraria Común o el Programa Leader, concluyendo que han sido orientadas claramente para garantizar medidas post-productivistas (Buller, Wilson y Höll 2000; Wilson 2001).

Si durante la Renaixença catalana se instaura el imaginario del Pirineo como eje articulador de la patria catalano-occitana (Verdaguer 1945; Balaguer 1968) el siglo XXI deja atrás el nacionalismo patrimonializador para centrarnos en una nueva realidad de consumo. Los valles del Alt Urgell realizan un esfuerzo para acoplarse al ritmo de la época y poco a poco pierden su énfasis productivo para vestirse de encanto. La imagen de estas montañas deja atrás las retóricas nacionalistas de un pasado triunfal plagado de batallas y leyendas heroicas, y en cambio se erige en bastión de la ruralidad, de los sabores y prácticas de antaño engalanadas por el color de lo auténtico. Se trata en suma de una revalorización basada en la nueva economía de los intangibles.

\section{CONCLUSIONES}

En este artículo hemos analizado la convergencia de estrategias y políticas que afectan tanto las zonas rurales como urbanas ante las transformaciones del capitalismo global. Hemos planteado una importante transformación en las lógicas que acompañan el desarrollo del constructo patrimonial desde el siglo XIX. Si en un principio nos referimos a un nacionalismo patrimonial centrado en la construcción de valores y representaciones de una nueva comunidad imaginada, el siglo XXI debe entenderse bajo los auspicios de un nuevo nacionalismo de consumo que adapta lo patrimonial a las dinámicas del mercado neoliberal. El reinado de la nueva economía de los intangibles marca nuevas pautas discursivas que transforman lo patrimonial, y deja atrás el énfasis en lo material para centrarse en nuevos valores y discursos de lo inmaterial.

El patrimonio y el turismo son las estrategias estrella de la nueva dinámica neoliberal para la reconversión de territorios, ya sean urbanos o rurales, que han visto morir el modo de producción que garantizaba su reproducción social ante las presiones de las dinámicas globales. La deslocalización y la crisis industrial que amenaza la supervivencia de las clases obreras en las ciudades tiene su réplica en la crisis de la agricultura intensiva orientada al mercado en algunas zonas rurales, ante la competencia de mercados integrados y las nuevas economías de escala que ponen en juego su supervivencia. En ambos casos llegan al rescate los discursos del turismo que acompañados de las narrativas patrimoniales garantizan nuevas ficciones que actúan como fuer- 
zas tanto centrípetas como centrífugas, y afectan así la construcción identitaria local y la imagen que se proyecta hacia afuera. Pero estos discursos asumen ropajes específicos, mientras Valencia apuesta por las infraestructuras creativas y la hipermodernidad, el Alt Urgell se viste de olor a campo y tradiciones, refugio de valores prístinos asociados al terruño y a lo natural. Ficciones ambas que se especializan según una nueva reordenación territorial que apuesta por los centros urbanos y condena a las periferias a convertirse en pueblos con encanto o a desaparecer en una oscuridad post-industrial.

Si bien consideramos importante destacar ciertas características comunes que impactan en diferentes territorios, lógicas y estrategias hermanas que se extienden a través de áreas muy diversas gracias a los mecanismos de difusión y producción del saber a nivel global, esto no supone hablar de homogeneización. De hecho, los estudios de globalización hace tiempo han destacado la importancia de lo local en la domesticación de lo global (Hannerz 1996; Appaurai 2001; Moore 2006). La expansión de discursos y dinámicas similares que afectan a territorios específicos es una realidad que no excluye la necesidad de estar atentos ante las particularidades de los modelos y la forma que adoptan en cada caso.

\section{BIBLIOGRAFÍA CITADA}

Abella, Jordi, Gabriel Alcalde y Antoni Rojas. 2012. "De la guadaña al forfait. Análisis del uso turístico de los museos etnológicos del Alto Pirineo catalán". Pasos. Revista de Turismo y patrimonio cultural 10(5): 619-628.

Adorno, Theodor y Max Horkheimer. 1994 [1944]. Dialéctica de la Ilustración. Fragmentos filosóficos. Madrid: Trotta.

Anderson, Benedict. 1983. Imagined communities: reflections on the origins and spread of capitalism. Londres: Verso.

Anheier, Helmut K. y Yudhishthir Raj Isar (eds.). 2008. Cultures and globalization: The cultural economy. Londres: Sage.

Appadurai, Arjun. 2001. La modernidad desbordada. Dimensiones culturales de la globalización. Buenos Aires: Fondo de Cultura Económica/Ediciones Trilce.

Ariño, Antonio. 2002. "La expansión del patrimonio cultural". Revista de Occidente 250: 129-150.

Balaguer, Víctor. 1968. Les esposalles de la morta. Raig de lluna. Barcelona: Edicions 62.

Ballart, Josep. 1997. El patrimonio histórico y arqueológico: Valor y uso. Barcelona: Ariel.

Belanger, Anouk. 2005. "Montréal vernaculaire/Montréal spectaculaire: dialectique de l'imaginaire urban". Sociologie et sociétés 37(1): 13-34.

Bell, David y Mark Jayne. 2010. "The creative countryside: policy and practice in the UK rural cultural economy". Journal of Rural Studies 26: 209-218.

Bendix, Regina F. 2009. "Heritage between Economy and Politics: An Assessment from the Perspective of Cultural Anthropology", en Laurajane Smith y Natsuko Akagawa (eds.), Intangible Heritage: 253-269. Londres: Routledge.

Bendix, Regina F., Aditya Eggert y Arnika Peselmann (eds.). 2012. Heritage Regimes and the State. Göttingen: Universitätsverlag Göttingen.

Bennet, Susan. 2005. "La scène spectaculaire de Toronto". Sociologie et sociétés 37(1): 109-123.

Benjamin, Walter. 2007. Illuminations. Essays and reflections. Nueva York: Schocken Books.

Boltanski, Luc y Ève Chiapello. 2002. El nuevo espíritu del capitalismo. Madrid: Akal.

Bortolotto, Chiara. 2011. "Le trouble du patrimoine culturel immatériel", en Chiara Bortolotto (ed.), Le patrimoine culturel immatériel : enjeux d'une nouvelle catégorie: 21-46. París: Éditions de la Maison des sciences de l'homme. 
Buscher, Bram, Sian Sullivan, Katja Neves, Jim Igoe y Dan Brockington. 2012. "Towards a synthesized critique of neoliberal biodiversity conservation”. Capitalism Nature Socialism 23(2): 4-30.

Buller, Henry, Geoff Wilson y Andreas Höll (eds.). 2000. Agri-environmental policy in the European Union. Aldershot: Ashgate.

Carrasco Campos, Ángel y Enric Saperas Lapiedra. 2011. "La institucionalización del concepto de industrias culturales en el proceso de debate sobre políticas culturales en la Unesco y el Consejo de Europa (1970-1982)". AdComunica. Revista de Estrategias, Tendencias e Innovación en Comunicación 2: 143-158.

Castells, Manuel. 1999. La Era de la Información. La sociedad red, vol. I. Madrid: Alianza Editorial.

Chaves, Margarita, Mauricio Montenegro y Marta Zambrano (eds.). 2014. El valor del patrimonio: mercado, politicas culturales y agenciamientos sociales. Bogotá: Instituto Colombiano de Antropología e Historia.

Choay, Françoise. 1996. L'allégorie du patrimoine. París: Seuil.

Cloke, Paul. 1989. "Rural geography and political economy", en Richard Peet y Nigel Thrift (eds.), New models in geography. The political-economy perspective: 164-197. Londres: Unwin Hyman.

Cloke, Paul y Mark Goodwin. 1992. "Conceptualizing countryside change: from post-Fordism to rural structured coherence". Transactions of the Institute of British Geographers 17: 321-336.

Comaroff, John L. y Jean Comaroff. 2009. Etnicidad S.A. Madrid: Katz.

Connolly, Mark G. 2013. "The "Liverpool model(s)": Cultural planning, Liverpool and capital of culture 2008". International Journal of Cultural Policy 19(2): 1-20.

Cucó, Josepa. 2013a. "Poniendo a Valencia en el mapa global. Políticas, desarrollos urbanos y narrativas sobre la ciudad", en Josepa Cucó (ed.), Metamorfosis urbanas. Ciudades españolas en la dinámica global: 157-180. Barcelona: Icaria.

Cucó, Josepa. 2013b. "Éxitos y perversiones en las fórmulas neoliberales. Los contrastes entre Barcelona, Bilbao y Valencia", en Josepa Cucó (dir.), La ciudad pervertida. Una mirada sobre la Valencia global: 213-232 Barcelona: Anthropos.

Daniels, Stephen. 1993. Fields of Vision: Landscape Imaginary and National Identity in England and the United States. Princeton: Princeton University Press.

Davallon, Jean. 2010. "The Game of Heritagization", en Xavier Roigé y Joan Frigolé (eds.), Constructing Cultural and Natural Heritage. Parks, Museums and Rural Heritage: 27-38. Girona: ICRPC.

Del Mármol, Camila. 2012. Pasados locales, políticas globales. Valencia: Germania-AVA.

Del Mármol, Camila. 2016. Muntanyes de Formatge: transformacions productives i patrimonialització al Baridà i l'Urgellet. Barcelona: Generalitat de Catalunya.

Del Mármol, Camila. 2017. "The quest for a traditional style: architecture and heritage processes in a Pyrenean valley". International Journal of Heritage Studies 23(10): 946-960. doi: 10.1080/ 13527258.2017 .1347888

Del Mármol, Camila e Ismael Vaccaro. 2015. "Changing Ruralities: between Abandonment and Redefinition in the Catalan Pyrenees". Anthropological Forum: A Journal of Social Anthropology and Comparative Sociology 25(1): 21-41.

Delgado, Manuel. 2007. La ciudad mentirosa. Fraude y miseria del modelo Barcelona. Madrid: La Catarata.

Díaz Orueta, Fernando. 2009. «El impacto de los megaproyectos en las ciudades españolas. Hacia una agenda de investigación". Estudios demográficos y urbanos 24(1): 193-218.

Díaz Orueta, Fernando. 2010. "Regímenes urbanos y movimiento ciudadano en Valencia”. Cuaderno Urbano 9(9): 275-294.

Esteban, Iñaki. 2007. El efecto Guggenheim, del espacio basura al ornamento. Barcelona: Anagrama.

Foucault, Michael. 1970. The Order of Things: An Archaeology of the Human Sciences. Londres: Tavistock.

Franquesa, Jaume. 2013. Urbanismo neoliberal, negocio inmobiliario y vida vecinal. El caso de Palma. Barcelona: Icaria.

Frigolé, Joan. 2005. Dones que anaven pel món. Estudi etnogràfic de les trementinaires de la Vall de la Vansa $i$ Tuixent (Alt Urgell). Barcelona: Generalitat de Catalunya. 
Frigolé, Joan. 2012. "Cosmologías, ecosímbolos y patrimonialización en el Pirineo catalàn en un contexto global». Revista de Antropología Social 21: 173-196.

Frigolé, Joan. 2014. "Retóricas de la autenticidad en el capitalismo avanzado". Endoxa 33: 37-60.

Gaja, Fernando. 2008. "El "tsunami urbanizador" en el litoral mediterráneo. El ciclo de hiperproducción inmobiliaria 1996-2006". Scripta Nova. Revista electrónica de geografía y ciencias sociales XII, 270 (66): [s. p.]. Disponible en: <http://www.ub.es/geocrit/sn/sn-270/sn-270-66.htm>. Fecha de acceso: 15 sep. 2017.

García, Beatriz. 2004. «Urban regeneration, arts programming and major events: Glasgow 1990, Sydney 2000 and Barcelona 2004”. International Journal of Cultural Policy 10(1): 103-118.

García, Beatriz. 2008. "Política cultural y regeneración urbana en las ciudades de Europa Occidental: lecciones aprendidas de la experiencia y perspectivas para el futuro". Revista de Investigaciones Políticas y Sociológicas 7(1): 111-126.

García, José Luis. 1998. "De la cultura como patrimonio al patrimonio cultural”. Política y Sociedad 27: 9-20.

García Canclini, Nestor. 1999. La globalización imaginada. Buenos Aires: Paidós.

Hannerz, Ulf. 1996. Transnational Connections: Culture, People, Places. Londres: Routledge.

Haraway, Donna J. 1995. Ciencia, cyborgs y mujeres. La reinvención de la naturaleza. Madrid: Cátedra.

Harrison, Rodney. 2013. Heritage: critical approaches. Londres: Routledge.

Harvey, David. 1991. "The urban face of capitalism", en J. Hung (ed.), Our changing cities: 50-66. Baltimore: John Hopskins University Press.

Harvey, David. 1998. La condición de la posmodernidad. Investigación sobre los orígenes del cambio cultural. Buenos Aires: Amorrurtu.

Harvey, David. 2005. A brief history of neoliberalism. Oxford: Oxford University Press.

Harvey, David. 2012. El enigma del capital y las crisis del capitalismo. Madrid: Akal

Heinich, Nathalie. 2009. La fabrique du patrimoine. De la cathédrale à la petite cuillère. París: Maison des Sciences de l'Homme.

Hernández Hernández, Francisca. 2002. El patrimonio cultural: la memoria recuperada. Gijón: Trea.

Hernández i Martí, Gil. 2004. "La desterritorialització del patrimoni cultural en la modernitat globalitzada". El Contemporani 30: 41-47.

Hernández, Gil M., Beatriz Santamarina, Albert Moncusí, y María Albert. 2005. La memoria construida. Patrimonio cultural y modernidad. Valencia: Tirant Lo Blanch.

Hesmondhalgh, David. 2007. The cultural industries. Londres: Sage

Hobsbawm, Eric y Terence Ranger. 1988. L'invent de la tradició. Vic: Eumo.

Holmes, George. 2011. "Conservation's Friends in High Places: Neoliberalism, Networks, and the Transnational Conservation Elite». Global Environmental Politics 11(4): 1-21.

Igoe, Jim, Katja Neves y Dan Brockington. 2010. "A Spectacular Eco-Tour around the Historic Bloc: Theorising the Convergence of Biodiversity Conservation and Capitalist Expansion" Antipode 42(3): 486-512.

Gold, John R. y Margaret M. Gold. 2008. «Olympic Cities: Regeneration, City Rebranding and Changing Urban Agendas". Geography Compass 2(1): 300-318.

Kavaratzis, Mihalis y Gregory J. Ashworth. 2005. "City branding: An effective assertion of identity or a transitory marketing trick?.. Tijdschrift voor Economische en Sociale Geografie 96(5): 506-514.

Kirshenblatt-Gimblett, Barbara. 2004. "Intangible Heritage as Metacultural Production". Museum international 56 (1-2): 52-65.

Lacarrrieu, Monica. 2008. "Es necesario gestionar el patrimonio inmaterial? Notas y reflexiones para repensar las estrategias políticas y de gestión”. Boletín Gestión Cultural 17: 2-26.

Latour, Bruno. 1993. Nunca hemos sido modernos. Ensayo de antropología simétrica. Madrid: Debate.

Lowe, Philippe, Jonathan Murdoch, Terry Marsden, Richard Munton y Andrew Flynn. 1993. «Regulating the new rural spaces: the uneven development of land". Journal of Rural Studies 9: 205-22.

Lowenthal, David. 1998. El pasado es un país extraño. Barcelona: Akal.

MacCannell, Dean. 1999. The Tourist: A New Theory of the Leisure Class. California: University of California Press. 
Macdonald, Sharon. 2013. Memorylands. Heritage and Identity in Europe Today. Londres: Routledge.

Markusen, Ann y Anne Gadwa. 2010. "Arts and culture in urban or regional planning: A review and research agenda". Journal of planning education and research 29(3): 379-391.

Marsden, Terry, Jonathan Murdoch, Peter Lowe, Richard Munton y Andrew Flynn. 1993. Constructing the countryside. Londres: UCL Press.

Marsden, Terry y Roberta Sonnino. 2008. "Rural development and the regional state: Denying multifunctional agriculture in the UK". Journal of Rural Studies 24: 422-431.

Martí, Javier. 2010. "Turismos y museos en la ciudad de Valencia", en Iñaki Arrieta (ed.). Museos y parques naturales: Comunidades locales, administraciones públicas y patrimonialización de la cultura y la naturaleza: 63-90. Bilbao: UPV.

Martínez Gallego, Francesc A. 2010. "Publicidad y turismo: la industria del forastero en la Exposición Regional de Valencia de 1909". Ámbitos 19: 161-182.

Mignolo, Walter D. 2012. Local histories/global designs: Coloniality, subaltern knowledges, and border thinking. Princeton: Princeton University Press.

Moore, Henrietta. 2006. "Global anxieties: concepts-metaphors and pre-theoretical commitments in anthropology", en Henrietta Moore y Todd Sanders (ed.), Anthropology in Theory. Issues in Epistemology, 443-455. Oxford: Blackwell Publishing.

Obiol, Emilio. 2009. "Geografía del Turismo en Valencia. Notas históricas. Los fundamentos del desarrollo turístico", en Jorge Hermosilla (ed.). La ciudad de Valencia, Historia, Geo-grafía y Arte: 91-103. Valencia: PUV.

Poulot, Dominique. 2006. Une histoire du patrimoine en Occident, XVIII-XIX siècle. Du monuments aux valeurs. París: Presses Universitaires de France.

Prats, Llorenç. 1997. Antropología y patrimonio. Barcelona: Ariel.

Prytherch, David L. 2009. "Elegy to an iconographic place: reconstructing the regionalism/ landscape dialectic in L'Horta de València". Cultural Geographies 16: 55-85.

Prytherch, David L. y Josep V. Boira y Maiques. 2009. "City profile: Valencia". Cities 2 (26): 103115.

Puche, Maika y Emilio Obiol. 2011 "Procesos de "re-imageneering" turístico: el eclipse de la identidad local de Valencia". Cuadernos de Turismo 28: 191-214.

Rausell, Pau. 2006. "Consideraciones globales hacia el tránsito de Valencia como una Ciudad Global". Ciudades 71: 49-57.

Rausell, Pau. 2010. "Valencia desde la huerta al ocio", en Josep Sorribes (ed.), Valencia, 1957-2007. De la riada a la Copa del América: 79-100. Valencia: PUV.

Rius-Ulldemolins, Joaquim, Gil-Manuel Hernández i Martí y Francisco Torres. 2016. "Urban Development and Cultural Policy "White Elephants": Barcelona and Valencia". European Planning Studies 24(1): 61-75.

Rodríguez, Arantxa. 2013. "Regeneración urbana en Bilbao: una metamorfosis ejemplar?», en Josepa Cucó (ed.), Metamorfosis urbanas. Ciudades españolas en la dinámica global: 229-257. Barcelona: Icaria.

Rodríguez, Arantxa y Lorenzo Vicario. 2005. "Innovación, competitividad y regeneración urbana: los espacios retóricos de la "ciudad creativa" en el nuevo Bilbao". Ekonomiaz 58: 262-295.

Roigé, Xavier y Joan Frigolé (eds.). 2010. Constructing cultural and natural heritage. Parks, museums and rural heritage. Girona: ICRPC.

Ruiz, Miquel y Beatriz Santamarina. 2013. "La Valencia bipolar y trepitante: discursos y representaciones sobre la transformación urbana", en Josepa Cucó (dir.), La ciudad pervertida. Una mirada sobre la Valencia global: 117-140. Barcelona: Anthropos.

Santamarina, Beatriz. 2008. "De la educación a la interpretación patrimonial. Patrimonio, interpretación y antropología", en Xerardo Pereira, Santiago Prado y Hiroko Takenaka, Patrimonios culturales: educación e interpretación: 39-56. Donostia: Ankulegi.

Santamarina, Beatriz. 2013. "Los mapas geopolíticos de la Unesco: entre la distinción y la diferencia están las asimetrías". Revista de Antropología Social 22: 263-286.

Santamarina, Beatriz. 2014. "La ciudad suplantada. Percepciones sobre los nuevos imaginarios (turísticos) de la ciudad de Valencia". Pasos: Revista de turismo y patrimonio cultural 12(4): 707718. 
Santamarina, Beatriz. 2016. "La naturaleza de las naturalezas patrimonializadas. Una aproximación a las formas hegemónicas de representar lo natural". Arxiu d'Etnografia de Catalunya 16: 153-177.

Santamarina, Beatriz y Albert Moncusí. 2013a. "De huertas y barracas a galaxias faraónicas. Percepciones sociales sobre la mutación de la ciudad de Valencia". Papers: revista de Sociología 98: 365-391.

Santamarina, Beatriz y Albert Moncusí. 2013b. "Manifiestos y latencias en la Valencia de las Guías Turísticas", en Josepa Cucó (ed.), Metamorfosis urbanas. Ciudades españolas en la dinámica global: 259-283. Barcelona: Icaria.

Santamarina, Beatriz y Albert Moncusí. 2013c. "El ensueño de Valencia y sus imágenes", en Josepa Cucó (dir.), La ciudad pervertida. Una mirada sobre la Valencia global: 95-116. Barcelona: Anthropos.

Santamarina, Beatriz y Albert Moncusí. 2015. "El mercado de la autenticidad: las nuevas ficciones patrimoniales". Revista de Occidente 440-441: 93-112.

Scott, Allen J. 2007. "Capitalism and urbanization in a new key? The cognitive-cultural dimension". Social Forces 85(4): 1465-1482.

Scott, Allen J. 2008. Social Economy of the Metropolis: Cognitive-Cultural Capitalism and the Global Resurgence of Cities: Cognitive-Cultural Capitalism and the Global Resurgence of Cities. Oxford: Oxford University Press.

Seisdedos, Hermenegildo. 2006. "La marca ciudad como antídoto para la bonsainización del citymarketing". Marketing $y$ Ventas. Disponible en $<$ http://www.labce.es $>$. Fecha de acceso: 9 ene. 2017.

Seisdedos, Hermenegildo. 2008. "Nosotras, las ciudades: estrategias urbanas para una ética del cuidado o qué hacer cuando mis proyectos estrella se convierten en elefantes blancos". Análisis local 81: 7-20.

Sivaramakrishnan, Kalyanakrishnan e Ismael Vaccaro. 2006. "Postindustrial Natures: Hyper-mobility and Place Attachments". Journal of Social Anthropology 14(3): 301-317.

Smith, Laurajane. 2004. Archaeological Theory and the Politics of Cultural Heritage. Londres: Routledge.

Smith, Laurajane. 2006. Uses of heritage. Nueva York: Routledge.

Smith, Laurajane y Natsuko Akagawa (eds.). 2009. Intangible Heritage. Londres: Routledge.

Swyngedouw, Erick, Frank Moulaert y Arantxa Rodríguez. 2002. "Neoliberal Urbanization in Europe: Large-Scale Urban Development Projects and the New Urban Policy". Antipode 34(3): 542-577.

Throsby, David. 2001. Economics and Culture. Cambridge: Cambridge University Press.

Treanor, Paul. 2005. Neoliberalism: origins, theory, definition. Disponible en: <http://web.inter.nl.net/ users/Paul.Treanor/neoliberalism.html>. Fecha de acceso: 15 dic. 2016.

Tulla, Antoni. 1994. Procés de transformació agrària en àrees de muntanya. Les explotacions de producció lletera com a motor de canvi a les comarques de la Cerdanya, el Capcir, l'Alt Urgell $i$ el Principat d'Andorra. Barcelona: Institut Cartogràfic de Catalunya. Col. Tesis doctorals.

Verdaguer, Jacint. 1945. Canigó. Vic: Llibreria Sala.

Vlès, Vincent. 2014. Métastations: Mutations urbaines des stations de montagne - Un regard pyrénéen. Burdeos: Presses Universitaires Bordeaux.

Williams, Raymond. 2001. El campo y la ciudad. Buenos Aires: Paidós.

Wilson, Graham. 2001. "From Productivism to Post-Productivism... and Back again? Exploring the (Un)changed Natural and Mental Landscapes of European Agriculturem. Transactions of the Institute of British Geographers 26(1): 77-102.

Wilson, Graham. 2007. Multifunctional agriculture: A transition theory perspective. Londres: Cromwell Press.

Woods, Michael. 2012. "Editorial: New directions in Rural Studies". Journal of Rural Studies 28: 1-4.

Woods, Michael y John McDonagh. 2011. "Rural Europe and the World: Globalization and Rural Development (Editorial)». European Countryside 3: 153-163.

Fecha de recepción: 17 de enero de 2017

Fecha de aceptación: 27 de julio de 2017 